\title{
Projected distributions of Southern Ocean albatrosses, petrels and fisheries as a consequence of
}

climatic change

L. Krüger ${ }^{1,7}$, J. A. Ramos ${ }^{1}$, J. C. Xavier ${ }^{1,2}$, D. Grémillet ${ }^{3,4}$, J. González-Solís ${ }^{5}$, M. V. Petry ${ }^{6,7}$, R. A. Phillips $^{2}$, R. M. Wanless ${ }^{4,8}$, V. H. Paiva ${ }^{1}$

${ }^{1}$ Marine and Environmental Science Centre MARE, Faculty of Science and Technology, University of Coimbra, Coimbra, Portugal

${ }^{2}$ British Antarctic Survey, Natural Environment Research Council, Cambridge, UK

${ }^{3}$ Centre d'Ecologie Fonctionnelle et Evolutive, UMR 5175, CNRS - Université de Montpellier Université Paul-Valéry Montpellier - EPHE, Montpellier, France

${ }^{4}$ Percy FitzPatrick Institute of African Ornithology, DST-NRF Centre of Excellence, University of Cape Town, Rondebosch, South Africa

${ }^{5}$ Department of Animal Biology, Faculty of Biology, University of Barcelona, Spain

${ }^{6}$ Laboratório de Ornitologia e Animais Marinhos, Universidade do Vale do Rio dos Sinos, São Leopoldo, Brasil

${ }^{7}$ Instituto Nacional de Ciência e Tecnologia Antártico de Pesquisas Ambientais INCT-APA, Brasil

${ }^{8}$ Seabird Conservation Programme, BirdLife South Africa, Private Bag X5000, 2121, Johannesburg, South Africa

Corresponding author: L. Krüger, Marine and Environmental Science Centre MARE, Faculty of Science and Technology, University of Coimbra, Coimbra, Portugal. E-mail: biokruger@gmail.com

Decision date: $21-\mathrm{Feb}-2017$

This article has been accepted for publication and undergone full peer review but has not been through the copyediting, typesetting, pagination and proofreading process, which may lead to differences between this version and the Version of Record. Please cite this article as doi: [10.1111/ecog.02590].

'This article is protected by copyright. All rights reserved.' 
Abstract. Given the major ongoing influence of environmental change on the oceans, there is a need to understand and predict the future distributions of marine species in order to plan appropriate mitigation to conserve vulnerable species and ecosystems. In this study we use tracking data from seven large seabird species of the Southern Ocean (Black-browed Albatross Thalassarche melanophris, Grey-headed Albatross T. chrysostoma, Northern Giant Petrel Macronectes halli, Southern Giant Petrel M. giganteus, Tristan Albatross Diomedea dabbenena Wandering Albatross D. exulans and White-chinned Petrel Procellaria aequinoctialis, and on fishing effort in two types of fisheries (characterised by low or highbycatch rates), to model the associations with environmental variables (bathymetry, chlorophyll-a concentration, sea surface temperature and wind speed) through ensemble Species Distribution Models. We then project these distributions according to four climate change scenarios built by the Intergovernmental Panel for Climate Change for 2050 and 2100. The resulting projections were consistent across scenarios, indicating that there is a strong likelihood of poleward shifts in distribution of seabirds, and several range contractions (resulting from a shift in the northern, but no change in the southern limit of the range in four species). Current trends for southerly shifts in fisheries distributions are also set to continue under these climate change scenarios at least until 2100; some of these may reflect habitat loss for target species that are already over-fished. It is of particular concern that a shift in the distribution of several highly threatened seabird species would increase their overlap with fisheries where there is a high-bycatch risk. Under such scenarios, the associated shifts in distribution of seabirds and increases in bycatch risk will require much-improved fisheries management in these sensitive areas to minimise impacts on populations in decline.

Keywords: Geographic Information System, Representative Concentration Pathways, Seabirds, Species Distribution Modelling, Tracking

'This article is protected by copyright. All rights reserved.' 


\section{Introduction}

Concern has increased over recent decades about the effects of anthropogenic changes in marine environments, including on biodiversity (Vitousek et al. 1997, Worm et al. 2006, Chown et al. 2015, Halpern et al. 2015). In particular, human impacts on the biosphere may exceed points of no-return; for instance, the effects of increased atmospheric carbon dioxide concentrations are believed to be irreversible on millennial timescales (Frölicher and Joos 2010), and the rate of biodiversity loss on the planet far exceeds the natural pace (Rockström et al. 2009). Research on the spatial effects of anthropogenic climate change shows that organisms may no longer encounter optimal conditions in terms of their thermal niche (Doney et al. 2012), and will be forced to shift their distribution (Walther 2010, Ackerly et al. 2010, Burrows et al. 2011, García Molinos et al. 2015). This may lead to impacts on community networks, for instance, changing food web connections (Parmesan 2006, Walther 2010, Constable et al. 2014), culminating in a cascade of extinctions within ecosystems (Thomas et al. 2004, Cheung et al. 2009, Stuart-Smith et al. 2015). This is of particular concern for oceanic regions, as many areas of high marine biodiversity are experiencing high rates of climate changes (Burrows et al. 2011, Constable et al. 2014, Marzloff et al. 2016).

Marine top predators often forage over very large oceanic areas and are exposed to a wide range of environmental conditions, thus providing good indicator species for evaluating long-term effects of climate change at large scales (Frederiksen et al. 2006, Sergio et al. 2008). Many empirical and theoretical studies provide evidence for shifts in distribution of marine species, including predatory fish and seabirds, following the movement of particular temperature isotherms towards higher latitudes (Cheung et al. 2009, Péron et al. 2010, Barbraud et al. 2012, Peron et al. 2012, Jones et al. 2013, Robinson et al. 2015, Sunday et al. 2015). Seabirds are distributed worldwide, are relatively easy to track, and are often used as models for testing the effects of climate variability on top-predators (Péron et al. 2010, 2012, Weimerskirch et al. 2012) and their prey (Xavier et al. 2006). Short-term responses of seabirds to climate change include reduced breeding success and body condition as the changing environment requires that seabirds travel longer distances to find optimal foraging grounds with increasing energy expenditure as consequence of central-place foraging (Dorresteijn et al. 2012, Péron et al. 2012, Paiva et al. 2013a, b), which in the long-term may result in population decreases (Grémillet and Boulinier 2009, Barbraud et al. 2012). For instance, Péron et al. (2010) reported that Wandering Albatross Diomedea exulans and Prions Pachyptila spp. moved poleward within a decade while White-chinned 
Petrels Procellaria aequinoctialis moved northward, which can be explained, at least partially, by changes in sea surface temperature and wind speed. Weimerskirch et al. (2012) found a consistent poleward shift by Wandering Albatrosses in two decades, which was related to an increase in zonal wind speed towards the south. Foraging ranges of breeding King Penguin Aptenodytes patagonicus increased as sea surface temperature increased (Péron et al. 2012). Such warming could explain recent reports of breeding attempts at new, higher latitude sites by King Penguins (Petry et al. 2013) and Macaroni Penguins Eudyptes chrysolophus (Gorman et al. 2010). Furthermore, several studies have documented the effects of climate stochasticity on population dynamics of seabirds (Croxall et al. 2002, Rolland et al. 2010, Barbraud et al. 2012).

Besides climate change, another anthropogenic stressor with a major impact on marine biodiversity is fisheries (Worm et al. 2006,Grémillet and Boulinier 2009, Halpern et al. 2015). Impacts include a reduction in fish populations from overfishing (Pauly et al. 1998, Daskalov 2002, Scheffer et al. 2005) and incidental mortality (bycatch) of non-target organisms such as seabirds, marine mammals or sea turtles (Jiménez et al. 2010, Lewison et al. 2014), with repercussions for food webs contributing to biodiversity loss (Pauly et al. 1998, Scheffer et al. 2005, Daskalov et al. 2007) ecosystem simplification (Scheffer et al. 2005, Möllmann et al. 2008, Howarth et al. 2014) and loss of ecosystem services (Worm et al. 2006). Climate change and fisheries may cause synergistic effects on species and populations (Walther 2010, Rolland et al. 2010, Thomson et al. 2015). Bycatch in fisheries is one of the main causes for the alarming declines and high threat of extinction of albatrosses and large petrels (Croxall et al. 2012), with 100,000s of birds killed annually (Anderson et al. 2011, Žydelis et al. 2013). Fisheries distribution is often correlated with oceanographic indices, as the target species are usually associated with upwelling or temperature gradients (Santos 2000, Solanki et al. 2005, Klemas 2013), so it is likely that fisheries are also affected by climate change (Pinnegar et al. 2002, Perry et al. 2005, Brander 2010), and conflicts between conservation and fisheries may increase due climate change (Hobday et al. 2015a, b). Hence, understanding whether shifts in seabird distribution due to climate change may lead to greater overlap with fisheries is of high importance for their conservation. The southern oceans are rich in terms of diversity and abundance of seabirds, and include several major global resource hotspots (Karpouzi et al. 2007, Lascelles et al. 2016). Although the regions of greatest overlap between seabirds and fisheries may include only part of the overall distribution of those species (Karpouzi et al. 2007), seabird bycatch

'This article is protected by copyright. All rights reserved.' 
rates in these areas can be high and have severe effects at the population level (Xavier et al. 2004, Lewison et al. 2014).

In this study we predict the distributions of multiple species of albatrosses and petrels, and fisheries, in the southern oceans under current climate conditions, and then project these distribution based on the Intergovernmental Panel for Climate Change (IPCC) scenarios for the years 2050 and 2100. Our goal was to evaluate shifts in distribution of both selected seabird species and fisheries, and to quantify likely changes in the resulting overlap. We used an ensemble Species Distribution Model (SDM) procedure to make robust predictions and projections (Morin and Thuiller 2009, Goberville et al. 2015). Based on the literature we anticipated that most species will lose previously suitable habitat and will likely show a poleward shift in distribution. We also expected that these latitudinal shift in distribution will lead to higher overlap with fisheries, as these are, similarly, likely to move, thus increasing the likelihood of seabird bycatch events. Indeed, the most challenging science issues in the coming decades is to assess the synergetic effects between climate change and fisheries on the food webs of the Southern Ocean (Kennicutt et al. 2014a, b)

\section{Methods}

\section{Seabird Tracking}

We used data collected from the following seabird species using Global Location Sensing (GLS) loggers: Black-browed Albatrosses Thalassarche melanophis from Bird Island, South Georgia (Phillips et al. 2005, Mackley et al. 2010) and New Island, Falkland Islands (Grémillet et al. 2000), Grey-headed Albatrosses T. chrysostoma from Bird Island, South Georgia (Croxall et al. 2005), Northern Giant Petrels Macronectes halli from Bird Island, South Georgia (González-Solís et al. 2008), Southern Giant Petrels M. giganteus from Bird Island, South Georgia (González-Solís et al. 2008) and from Elephant Island, South Shetland Islands (Krüger et al. in prep), Tristan Albatrosses Diomedea dabbenena from Gough Island (Reid et al. 2013), Wandering Albatrosses D. exulans from Bird Island, South Georgia (Mackley et al. 2010) and White-chinned Petrels Procellaria aequinoctialis from Bird Island, South Georgia (Phillips et al. 2006) (Supplementary material Appendix 1, Table A1).

\section{Climate and environmental variables}

The environmental predictors used in the SDMs were Sea Surface Temperature (SST), Chlorophyll-a Concentration (CHL), Wind speed (WIND), Ice Cover (ICE) and Bathymetry (BATH) downloaded from 
the NOAA CoastWatch browser (coastwatch.pfeg.noaa.gov/coastwatch) (Supplementary material Appendix 1, Table A2, Fig.A1). We choose these variables because other studies showed that they are good proxies for seabird distribution and habitat use (Catry et al. 2013), with several studies pointing out these as the most important in seabird modelling (Hazen et al. 2012, Quillfeldt et al. 2013, Legrand et al. 2016). Furthermore there is empirical evidence for some seabird populations of shifts in distributions in response to spatial changes in some of those variables (i.e. Péron et al. 2010, Weimerskirch et al. 2012). We processed these data in ESRI ArcGIS 10.2 to extract annual means on a $1^{\circ} \mathrm{x} 1^{\circ}$ grid size, which corresponds to the mean error of the tracking devices ( $\approx 180 \mathrm{~km}$; Phillips et al. 2004).

\section{Seabird distribution modelling}

We estimated suitable habitat for the study species in the Southern Ocean by combining tracking data with environmental predictors through an ensemble Species Distribution Modelling approach (Oppel et al. 2012, Scales et al. 2016) using the 'Biomod2' package (Thuiller 2003, Thuiller et al. 2009) within the R environment (R Core Team 2015). Slight differences in species distributions among models increases when distribution are forecasted towards future projections even for models with similar outputs in current predictions (Elith et al. 2010, Goberville et al. 2015); however, the use of ensemble models improve results by reducing bias and problems associated with over-fitting (Thuiller et al. 2009, Elith et al. 2010, Scales et al. 2016). The logic behind ensemble modelling is that the final distribution is a joint solution that combines all the models 'emphasizing the 'signal' emerging from the noise associated with different model outputs" (Araújo and New 2007) then forecasting species' distribution in a more conservative way, under uncertainties of projected environmental variables (Thuiller 2004, Araújo and New 2007, Thuiller et al. 2009, Zhang et al. 2015). For detailed discussions on the pros and cons of Species Distribution Models, please see Thuiller (2003, 2004), Araújo and New (2007), Lozier et al. (2009), Thuiller et al. (2009), Planque (2016) and Zhang et al. (2015). For details and parameters of the models we used on our analysis, see Supplementary material Appendix 1, Table A3.

As GLS data provide presence-only data, SDM require the creation of pseudo-absences to calculate probabilistic relations of distribution with environmental variables (VanDerWal et al. 2009, Barbet-Massin et al. 2012). We created 10,000 pseudo-absences using the species range exclusion 'sre' method, which forces the pseudo-absences to be generated from within the core habitat area used by the species (Barbet-Massin et al. 2012, Legrand et al. 2016). We applied a cross-validation procedure by setting aside $80 \%$ of the data-set for training the models and $20 \%$ for evaluation.

'This article is protected by copyright. All rights reserved.' 
After the modelling we generated ensembles predictions and projections of occurrence using the full dataset and statistic models (check 'models assembly rules' on Thuiller et al. 2014). The models were permuted 10 times for training/calibrating and to calculate the importance of variables, which is measured as the change in the models' accuracy by excluding one variable in turn and retaining the remainder. We used the True Skill Statistic and Area Under the Receiver Operational Characteristic Curve AUC to evaluate model accuracy (Allouche et al. 2006, Liu et al. 2009). AUC and TSS both compare Sensitivity and Specificity outputs between the $80 \%$ data used for calibration with the $20 \%$ used for evaluation. Sensitivity measures the percentage of presence cases that are classified correctly (true positive rate) by the models, and Specificity measures the percentage of pseudo-absences cases correctly classified as absences (true negative rate) by the models. Accuracy can be linked to the number of presences (Hernández et al. 2006, Wisz et al. 2008), the method of generating pseudo-absences and the number of pseudo-absences (Barbet-Massin et al. 2012). An excessive number of pseudo-absences when there are fewer presences can inflate the accuracy of the models, which in our case is not a problem considering the large numbers of presence points. On the other hand, an increasing number of presences makes the relation of distribution with environmental variables more robust, thus increasing models' accuracy (Hernández et al. 2006, Wisz et al. 2008).

\section{Climate and Species projections}

The IPCC developed four scenarios for climate change based on the Coupled Model Intercomparison Project CMIP5, called Representative Concentration Pathways (RCPs). RCPs are based on different greenhouse gas and air pollutants emissions and their radiative forcing (IPCC 2014). One scenario assume low emissions with global temperature remaining close to the pre-industrial climate (RCP 2.6), two scenarios assumes intermediate emissions (RCP 4.5 and RCP 6.0) and one scenario assumes high emissions (RCP 8.5). Environmental and climate variables were projected by the National Oceanic and Atmospheric Administration Geophysical Fluid Dynamics Laboratory (NOAA - GFDL), using the Coupled Climate-Carbon Earth System Models (ESM), which takes into account biogeochemical components that regulate carbon circulation on ocean, land, atmosphere and biosphere (IPCC 2014). Two distinct models are based on differential assumptions concerning vertical layers of ocean circulation, one based on water depth (ESM2M) and the other on water density (ESM2G) (Dunne et al. 2012, 2013). Both models are assumed to have high power of prediction (Dunne et al. 2012, 2013); however, we choose to use the projections of the ESM2M as its predictions for several ocean surface variables were slightly 
better than the ESM2G (Dunne et al. 2012). Projections generated from the ESM2M models were downloaded from the NOAA CMIP5 data portal (http://nomads.gfdl.noaa.gov). After applying SDM, we generated the ensemble mean statistic to predict species distributions using all the models. Those statistics were then applied to the climate projections for 2050 and 2100 under each RCP scenario. We also entered BATH in the projections as a fixed variable. We created polygons from the mean distribution provided by ensemble projections, using the mean threshold probability from the models with AUC > 0.9 and TSS > 0.8 for setting species presence (Jiménez-Valverde and Lobo 2007, Barbet-Massin et al. 2012). We opted for this level of accuracy because the 'sre' method for generating pseudo-absences tends towards overoptimistic models (Thuiller et al. 2014).

\section{Specific measures of change}

We used the polygons from the mean ensemble SDM to calculate the centre of the distribution for each species for predictions and projections. A latitudinal shift was calculated by subtracting the centre positions of the predictions from the respective centre positions of the projections. For instance, when the centre of distribution of a species moved south, the latitude range shift will be negative, and positive when it moved north. This corresponds to the number of degrees of dislodgement of the future distribution in relation to the current distribution. Habitat suitability change was calculated for each species based on the Species Range Change analysis (SRC) as the percentage of suitable habitat change, using the Biomod2 (Thuiller 2003, Thuiller et al. 2009). SRC varies between -100 and 100, where values below zero indicate range loss, values equal to zero indicate a stable range and values above zero indicate new habitats acquired.

\section{Fisheries projection}

Halpern et al. (2015) used catch data from the "Sea Around Us" project (http://www.seaaroundus.org/) to estimate the spatial distribution of industrial fishing effort, dividing fisheries into four main categories, based on the mean rates of overall bycatch (Watson et al. 2006): pelagic low-bycatch, pelagic highbycatch, demersal low-bycatch and demersal high-bycatch. By definition, low-bycatch fisheries were considered to be more selective in the number and type of organisms they catch, whereas the opposite applies to high-bycatch fisheries, which capture a higher proportion of non-target organisms and produce more discards (Hall et al. 2000, Pauly et al. 2002, Davies et al. 2009, Zhou et al. 2010). Hence, highbycatch fisheries may represent a greater threat for seabirds if there is also a high risk of seabird bycatch; 
however, they also provide a source of supplementary food. Discard volume and seabird bycatch risk are linked, since discarding attracts seabirds to fishing vessels, and in the absences of seabird bycatch mitigation, the number killed can be related to the number attending the fishing vessel (Yeh et al. 2013).

Fisheries distribution is often correlated with oceanographic predictors, as the target species are usually associated with upwelling or temperature gradients (Santos 2000, Solanki et al. 2005, Klemas 2013). Based on this assumption, we used catch data in Halpern et al. (2015) (https://knb.ecoinformatics.org/\#view/doi:10.5063/F1S180FS) to indicate fishery presence; any pixel with a catch value above the minimum value was considered to be a presence, hence selecting areas above the minimal fishing intensity (Supplementary material Appendix 1, Fig. A2), for high-bycatch fisheries $(\mathrm{n}=$ 4237 points) and low-bycatch fisheries ( $n=8091$ points). We entered these points in an ensemble modelling procedure, similar to the procedure used for seabird modelling, aiming to predict fisheries activities distribution and project the fishery activities' distribution towards the future climate change scenarios for years 2050 and 2100. As with seabirds, we generated polygons using threshold of the models with AUC > 0.9 and TSS $>0.8$.

It is important to note that the estimation of fisheries catch distribution in Halpern et al. (2015) was based on data from the Food and Agriculture Organizations of the United Nations (FAO), and likely to be substantial underestimates, as shown in catch reconstructions by Pauly and Zeller (2016). However, as we used a low recorded catch threshold to predict fisheries presence, our model is probably a good approximation, given that peaks in reconstructed catches match peaks in catches reported to the FAO (Pauly and Zeller 2016).

\section{Statistical Analysis}

\section{Species Distribution Changes}

We used Permutational Multivariate Analysis of Variance (PERMANOVA) implemented by the vegan R-package (Oksanen et al. 2012) to compare differences in Latitudinal Shift and Species Range Change (1) among each scenarios (Representative Concentration Pathway; RCP 2.6, RCP 4.5, RCP 6.0 and RCP 8.5) for 2050 and 2100 using species, and (2) among species, using scenarios, respectively, as the repetitions. The similarity metric was Euclidian distance, and significance was calculated by 999 permutations."

\section{Species and Fisheries Overlaps}

'This article is protected by copyright. All rights reserved.' 
We used Geographically Weighted Principal Component Analysis (GWPCA) on the GWmodel package in R environment ( $\mathrm{Lu}$ et al. 2014) to evaluate the shifts in seabird and fisheries distributions on a $5 \mathrm{x} 5$ degree spatial grid, using the probability of occurrence of each species and fisheries currently and for the year 2100. Geographically-weighted models account for local variation in the response variables that would not be detected by a simple global model (Lu et al. 2014). As biomod2 outputs are represented as percentages, data were arcsine transformed in order to meet the normality assumptions of PCA. GWPCA Significance was calculated using a Monte Carlo test, with 99 resampling events. To represent the variability in the overlaps in spatial terms, we mapped the local Cross-Validation scores of the GWPCA (Lu et al. 2014) interpolated on a spatial grid by a Natural Neighbour procedure in ArcGis 10.2 (Childs 2004). Cross-Validation scores represent the localized amount of variability captured in the GWPCA components, so are useful for visualising how the multivariate data behave spatially (Lu et al. 2014).

The GWPCA loadings represent the position of species and fisheries on each axis, and the distance between their centroids represents a quantification of their overlaps. So we measured the Euclidean distance of each species to fisheries in the bi-dimensional space of GWPCA in the prediction and in the scenarios. We subtracted the distance in the scenarios from the distance in the prediction in order to calculate shifts in levels of overlap with fisheries. Negative values would mean that a species increased its spatial overlap with fisheries (as it reduced its bi-dimensional distance from fisheries in the projections), whereas positive values mean that a species decreased its overlaps (as it increased its bidimensional distance from fisheries in the projections). Noteworthy current distribution and all projected scenarios were entered as separated variables in the same GWPCA, so changes in the bidimensional distance were always regarding spatial changes in time and scenarios, than simply a change in spatial overlap.

\section{Results}

\section{Seabird species - predicted and projected distributions}

Model's Accuracy was high for all species and models (AUC $>0.9$, TSS $>0.8$; Supplementary material Appendix 1, Table A4), except the model Multiple Adaptive Regression Splines for Black-browed Albatross $($ AUC $=0.775$, TSS $=0.531)$. Sea Surface Temperature $(\mathrm{SST})$ had the highest permutation importance for most species $(0.523 \pm 0.19)$ usually followed by CHL $(0.240 \pm 0.20)$ or WIND $(0.186 \pm$ 0.06), with the exception of White-chinned Petrel (CHL $=0.661$ vs SST $=0.325)$ (Supplementary 
material Appendix 1, Table A4). A visual comparison between predictions and projections indicates clearly that suitable habitat moved south for all species, and most species lost suitable habitat (Fig. 1; Supplementary material Appendix 1, Fig. A3 to A9).

\section{Fisheries predicted and projected distribution}

There was a high predictive power of the fisheries distribution models for both high-bycatch (AUC $=0.98$ $\pm 0.03, \mathrm{TSS}=0.90 \pm 0.05)$ and low-bycatch $(\mathrm{AUC}=0.96 \pm 0.03 ; \mathrm{TSS}=0.87 \pm 0.06 ;$ Supplementary material Appendix 1, Table A5), except Surface Range Envelop for low-bycatch fisheries (AUC = 0.89, TSS $=0.78$ ). Both high-and low-bycatch fisheries distributions were mostly related to WIND and SST (Supplementary material Appendix 1, Table A5). High-bycatch fisheries clearly gained habitat in southern waters, and occupied several previously unsuitable areas in tropical and subtropical waters (Fig. 2; Supplementary material Appendix 1, Fig. A10 ). Low-bycatch fisheries, despite maintaining the latitudinal range, were predicted to contract in overall range in all scenarios but gained new areas in the southeast Atlantic and south Pacific oceans (Fig. 2; Supplementary material Appendix 1, Fig. A11).

\section{Species Distribution Changes}

Neither Latitude Shift or Species Range Change differed among scenarios (PERMANOVA Pseudo-F $\mathrm{F}_{3,48}=$ $0.17, \mathrm{R}^{2}<0.01, \mathrm{p}=0.96$ ), between years 2050 and 2100 (PERMANOVA Pseudo- $\mathrm{F}_{1,48}=0.06, \mathrm{R}^{2}<0.01$, $\mathrm{p}=0.89$ ), nor their interaction (PERMANOVA Pseudo- $\mathrm{F}_{3,48}=0.15, \mathrm{R}^{2}<0.01, \mathrm{p}=0.98$ ). As these variables differed among species (PERMANOVA Pseudo- $\mathrm{F}_{6,49}=247.77, \mathrm{R}^{2}=0.96, \mathrm{p}<0.001$ ), scenarios cannot be compared readily across species; however, they can be used to evaluate changes within species. The mean suitable habitat of all species was displaced towards the south (Fig. 3a). Tristan Albatross and White-chinned Petrel showed the greatest Latitude Shift, moving almost $10^{\circ}$ towards the south (Fig. 3a). The range of Black-browed Albatross, Tristan Albatross, and White-chinned Petrel increased, but by < $10 \%$, whereas the ranges of Wandering Albatross and Grey-headed Albatross decreased substantially (by 70\%; Fig. 3b).

\section{Species and Fisheries overlaps}

The Geographically Weighted PCA axis one (PC1) captured $73.8 \%$ of the data variation, and axis two (PC2) captured the remaining 26.2\% (Monte-Carlo $\mathrm{p}=0.01$ ). The amount of variability captured by PC1 was clearly related to the segregation of fisheries (negative values) and seabirds (positive values) and was consistent in all Representative Concentration Pathway (RCP) scenarios (Fig. 4). In contrast, PC2 
captured the variability in the data regarding fisheries and seabird overlaps for year 2100 (positive values)

(Fig.4). The only species with negative values on PC2 for all scenarios was the Southern Giant Petrel, indicating the highest segregation from fisheries in relation to the prediction (Fig. 4). Most species converged in their distribution towards the same area (Wandering Albatross, White-chinned Petrel, Northern Giant Petrel, Grey-headed Albatross and Black-browed Albatross) in all the scenarios RCP 2.6 (Fig. 4b), RCP 4.5 (Fig. 4c), RCP 6.0 (Fig. 4d) and RCP 8.5 (Fig. 4e). The reduction in spatial overlap with fisheries for all scenarios (Fig. 4b, c, d, e) is more evident when the mean Principal Component distance from fisheries on projections is calculated (Fig 4f). Southern Giant Petrel moved the greatest distance from high-bycatch fisheries and both Grey-Headed Albatross and Wandering Albatross showed the smallest change (Fig. 4f). However, the distribution of low-bycatch fisheries suggests a resulting increase in likely levels of overlap with seabirds (Fig. 4b, c, d, e); indeed, only for Grey-Headed Albatross and Wandering Albatross was the overlap likely to be reduced. The greatest variability in the level of seabird-fisheries overlap was in temperate and Antarctic waters between $40^{\circ} \mathrm{S}$ and $60^{\circ} \mathrm{S}$ in both the Atlantic and Indian oceans, which coincides with areas where there was projected increases in species ranges and overlap with both low- and high-bycatch fisheries (Fig. 5).

\section{Discussion}

We found very high accuracy values for most models, which indicates that the group of variables selected for the models are excellent to predict spatial distribution of seabirds species, as it has been showed by other empirical and modelling studies (i.e., Pinaud and Weimerskirch 2007, Hazen et al. 2012, Legrand et al. 2016). In fact, Sea Surface Temperature, Chlorophyll-a concentration and Bathymetry have been demonstrated to be the best predictor variables to model the seabirds' spatial distribution (Hazen et al. 2012, Quillfeldt et al. 2013, Legrand et al. 2016), and Wind have been increasingly found to be of high importance to a multitude of seabirds (i.e. González-Solís et al. 2009, Adams and Flora 2009, Weimerskirch et al. 2012, Ramírez et al. 2013, Dehnhard et al. 2013, Legrand et al. 2016, Tarroux et al. 2016). Furthermore, using a smaller amount of key variables is a better approach than adding several correlated variables that could add noise to the modelling exercise and somehow hamper the models' predictive capacity to generate the projections (Merow et al. 2013). We have to acknowledge, however, the influence of scale on seabirds' habitat use (Hunt and Schneider 1987, Pinaud and Weimerskirch 2005, Thiebault and Tremblay 2013). But even at finer spatial and temporal scales those variables are still important for several seabird species (Pinaud and Weimerskirch 2005, 2007) even on modelling studies 
(Péron et al. 2012, Ludynia et al. 2013, Scales et al. 2016). Recent studies using a similar approach also produced accuracy values above 0.95 (i.e. Russell et al. 2015, Legrand et al. 2016).

\section{Seabird Species Distribution}

The change in seabird distribution that we found using the RCP scenarios matched the expectations of poleward shifts of marine predators according to several theoretical models (Lenoir et al. 2011, Hazen et al. 2012, Russell et al. 2015). However, we found that some species reduced their northern range without necessarily gaining new habitat towards the south. So, it is more accurate to say, at least for four species (Grey-headed Albatross, Northern and Southern giant petrels, Wandering Albatross), that there is likely to be a contraction in their northern distribution instead of poleward movements as a result of climate change. The three species that moved substantially poleward in our projections gained only small percentages of new habitat (Black-browed Albatross, Tristan Albatross and White-chinned Petrel). This is consistent with results of Russell et al. (2015) which projected that 15 out of 23 seabird species will reduce their range in European waters according to IPCC, with their main distributions also shifting poleward. Our results are also consistent with Hazen et al. (2012) which predicted range increases and poleward shifts for three procellariiform species in the northern Pacific Ocean. Range contraction and poleward shifts have been projected for several groups of marine and terrestrial organisms, including seaweed (Takao et al. 2015, Marzloff et al. 2016), marine fish (Lenoir et al. 2011, Hazen et al. 2012, Jones et al. 2013, Sunday et al. 2015), marine invertebrates (Cheung et al. 2009, Stuart-Smith et al. 2015, Sunday et al. 2015, Marzloff et al. 2016), marine mammals (Hazen et al. 2012), insects (Beaumont and Hughes 2002, Kwon and Lee 2015, Kwon et al. 2015), ticks (Williams et al. 2015), terrestrial birds (Araújo et al. 2005), and trees (Morin and Thuiller 2009, Goberville et al. 2015). Such changes were also projected to reflect in spatial redistribution of biodiversity with consequences for ecosystem functioning (Constable et al. 2014, Stuart-Smith et al. 2015, García Molinos et al. 2015).

Our predicted latitudinal shifts are within the range of those detected using empirical data on distributions of seabirds that have changed in the last two to three decades (Péron et al. 2010, Weimersirch et al. 2012). We found latitudinal shifts of Wandering Albatross which matched those reported by Weimerskirch et al. (2012); around $5^{\circ}$ towards the south. Perón et al. (2010) also report a poleward shift in the at-sea distributions of Wandering Albatrosses, Giant Petrels and White-chinned 
Petrels. Thus, we believe our findings are within realistic expectations. This is alarming, as two species in this study (Grey-headed Albatross and Wandering Albatross) were projected to experience a range contraction of almost $70 \%$, which was consistent for all scenarios for 2050 and 2100 . These two species are highly threatened with decreasing population trends - Grey-headed Albatross is Endangered (Birdlife International 2016a) and Wandering Albatross is Vulnerable (Birdlife International 2016b). The rate of breeding pairs' decline of Grey-headed Albatross, globally, is projected to be $65.4 \%$ (range $50 \%$ to $80 \%$ ) in three generations (Birdlife International 2016a), and of Wandering Albatross is expected to be $>30 \%$ in 70 years (Birdlife International 2016b), as both species presented population declines around one and five percent per year in the last decades (ACAP 2012). Most of those decreases are attributed to fisheries seabird bycatch, but losing suitable area due to climatic change would put extra pressure on such highly threatened species (Barbraud et al. 2012). At a smaller scale, there is the risk that favourable foraging habitat will move further from the breeding grounds (Ainley and Hyrenbach 2010, Péron et al. 2010), forcing seabirds to increase their foraging effort (Péron et al. 2012, Paiva et al. 2013a, b). However, changes in the environment can also have positive consequences, for example for Wandering Albatrosses which have shown long-term increases in foraging performance by reducing time spent commuting in faster winds; however, as climate change becomes more extreme, these benefits may disappear (Weimerskirch et al. 2012). Our results do not provide the temporal detail to evaluate whether favourable foraging habitat during incubation and chick-rearing would be at increasing distances from the respective colonies; however, for two species, the Tristan Albatross and the Grey-headed Albatross, the core of the year-round suitable habitat moves dangerously away from their breeding grounds. In the case of the Tristan Albatross it is critical as this species only breed regularly on Gough Island. Studies of habitat suitability at a finer temporal scale for this species are highly needed, as it is Critically Endangered.

\section{Fisheries Distribution}

We found an increase in suitable habitat for high-bycatch fisheries, which would increase the spatial and population impacts of this type of fishery, which is already widely distributed in global oceans and known to have major effects on food webs (Halpern et al. 2015). Industrial fisheries catches are decreasing (Pauly and Zeller 2016), following the decline of the main target stocks (Myers and Worm 2003, 2005, Brander 2010). However, even under the situation of decreasing and collapsing stocks, some fisheries have increased effort to compensate for the lower catch, i.e. increasing number of nets, hooks, fishing in remote areas, fishing deeper, and investing in technological advancements to locate and capture fish 
(Pauly et al. 2002, Brander 2010), so expanding their operational area to embrace a larger number of marine habitats. World Fisheries have been expanding since 1950 to occupy over almost all the open oceans in the last decades, avoiding only the least productive waters (Pauly et al. 2002, Swartz et al. 2010). Our projections showed that high-bycatch fisheries may expand towards areas that are currently unsuitable for fisheries, with potentially deleterious effects. Furthermore, as oceanographic conditions shift, fisheries may have to expand in overall extent to match the changing distribution of target species. Hence, the southward expansion of fishing activities that has progressed in the last 60 years (Swartz et al. 2010) may continue increasing to include more of the waters closer to what are currently subantarctic islands, and potentially further south into Antarctic.

On the other hand, low-bycatch fisheries reduced in the extent of suitable habitat in all scenarios. As this type of fishery is more selective (Pauly et al. 2002, Zhou et al. 2010), it is logical to assume that decreases in suitable areas reflects more closely the loss in habitat for the small number of target species. Selective fisheries are more efficient but may have large effects by removing high biomass of key species in ecosystems, with top-down effects on marine food webs and a high risk of massive over-fishing and stock collapse (Halpern et al. 2008, Zhou et al. 2010). Without effective management, these fisheries can rapidly become unsustainable (Pauly et al. 2002, Zhou et al. 2010), which is a key issue given that high seas management is considerably difficult (Hobday et al. 2015b). Such a trade-off between increased high-bycatch fisheries and decreased low-bycatch fisheries would support the call for the balanced fishing strategy proposed in response to climate change by Zhou et al. (2010).

Our results suggest that the impacts of fisheries on global oceans will increase under climate change unless there is improved management to reduce deleterious effects (high rates of bycatch and over-fishing). There are ways to do this such as using special baits to reduce seabird bycatch, fishing at night and setting economical penalties for bycatches (Cox et al. 2007, Tuck et al. 2011, Worm et al. 2009). However, effects of fisheries are likely to change with a shift in distribution if this involves a different targeted stock or fishing methods, which makes it difficult to anticipate the full consequences of climate change.

\section{Species and Fisheries overlaps}

Seabird population responses to the combined effects of climatic change and fisheries are highly variable (Barbraud et al. 2012). Studies have recorded increases (Delord et al. 2008, Péron et al. 2010, Rolland et 
al. 2010) or decreases in seabird abundance (Delord et al. 2008, Thomson et al. 2015) if conditions warm, that may compensate for, or exacerbate the population-level effects of incidental mortality and the energetic contribution from feeding on discards and offal (Rolland et al. 2010). Scavenger species may benefit from interactions with fisheries by feeding on discards if the bird bycatch rate is low (Furness et al. 2007). This is thought to explain increases in populations of several gull species (Bicknell et al. 2013), giant petrels (Quintana et al. 2006, Delord et al. 2008, Copello and Quintana 2009) and Black-browed Albatross (discards from trawl fishery increased breeding success, Rolland et al.2010). As high-bycatch fisheries often provide extensive discards (Hall et al. 2000, Harrington et al. 2005, Zhou et al. 2010), these scavenging seabirds could suffer under scenarios that predict reduced overlap. However, some scientists argue that it would be appropriate if population sizes of scavenging seabirds returned to levels typical of years prior to the advent of industrial fisheries because the current, artificially-high numbers can have major impacts on other types of prey, including smaller seabirds (Votier et al. 2004, Furness et al. 2007).

The main effects of fisheries on seabirds are population decreases due to incidental mortality (Rolland et al. 2010, Barbraud et al. 2012, Thomson et al. 2015), so increases in overlap with fisheries would entail a greater risk. Our results showed that several species would overlap less in the future with high-bycatch fisheries, independent of the climate change scenario. A tendency for a southerly shift to decouple bird from fisheries distributions in the Indian Ocean, and the conservation benefits, were stressed by Weimerskirch et al. (2012), and seem likely to occur elsewhere. However, species that were displaced from most of the projected distribution of high-bycatch fisheries also lost the northern portion of their current range, so the net response may be negative; indeed, for four species, the reduction in overlap with high-bycatch fisheries comes from range contraction. On the other hand, Wandering Albatross and Grey-headed Albatross, the two species with the highest range reduction, were predicted to increase their level of overlap with low-bycatch fisheries. As both species are declining largely because of incidental mortality, the consequences of climatic change are, ultimately, likely to reflect the extent to which measures are taken to minimise seabird bycatch by different fleets, which may vary a great deal (Waugh et al. 1999, Nel et al. 2003, Rolland et al. 2010, Tuck et al. 2011).

Overall there was a reduced overlap with fisheries for all scenarios, except for three main oceanic regions; northeast of the Antarctic Peninsula in the Scotia Sea, the central South Atlantic and the south Indian Ocean, where practically all species converged. Currently, there is little seabird bycatch in 
this first region, as the fisheries are well-regulated by the Commission for the Conservation of Antarctic Marine Living Resources (Waugh et al. 2008), contrasting to higher levels of bycatch further north within International Comission for the Conservation of Atlantic Tunas ICCAT or the Commission for the Conservation of Southern Blue-fin Tuna CCSBT areas (i.e. Bugoni et al. 2008, Yeh et al. 2013). The monitoring and standard of management of fishing practices in this area needs to be maintained, and in the other regions to improve in order to reduce the wider ecosystem-level impacts. Efforts to reduce incidental mortality and the amount of discarding are increasing including the development of technical solutions such as the use of 'hook Pods' (http://fishtekmarine.com/hookpod.php) (Gilman et al. 2005, Bull 2007, Pascoe et al. 2013), and initiatives that increase public awareness of the actions needed to protect seabirds, like the Save the Albatross campaign hosted by The Royal Society for the Protection of Birds (http://www.rspb.org.uk/joinandhelp/donations/campaigns/albatross/index.aspx), or the Agreement on the Conservation of Albatrosses and Petrels (http://www.acap.aq/). Improved management of both bycatch and discards would also benefit other aquatic wildlife and the overall health of marine ecosystems (Furness et al. 2007, Bellido et al. 2011), and there are several possibilities of fisheries management approaches taking in account climate change scenarios to which base present and future actions (i.e., Hobday et al. 2015b, Ogier et al. 2016).

\section{Conclusions}

Consistent trends towards range contraction and poleward shift of Southern Ocean seabirds trigger an alarm to conservationists. Climate change may alter the suitability of habitat for several species and limit their distribution within our (and individual seabirds') lifetime. Seabirds' populations may start to experience the effects of increased costs to find food and deteriorated environmental condition within four decades. It would also require a dramatic change on the location of priority areas for conservation in the Oceans, which is nowadays a troublesome topic. A likely convergence of several highly threatened seabird species towards areas of high risk of bycatch also displaced by climate change, poses the need to continuously monitor fisheries and when needed mitigate bycatch of seabirds and other marine taxa. Reduced ranges for low-bycatch (selective) fisheries should be viewed with caution, as this may in fact be depicting a low abundance of target prey-species which may already be at risk from over-fishing.

Acknowledgements - L.K. acknowledges the National Council of Technological and Scientific Development CNPq for his PhD scholarship (Programa Ciência sem Fronteiras processo 245540/2012-1). V.H.P. acknowledge the support given by 'Fundação para a Ciência e Tecnologia' 
(SFRH/BD/47467/2008 and SFRH/BPD/85024/2012) and the Biodiversity Research Institute (IRBio).

J.C.X. was supported by the Investigator FCT program (IF/00616/2013). We acknowledge the Brazilian Navy for field research support in Antarctica for collecting data of Southern Giant Petrels at Elephant Island, which also received funding from the National Institute of Science and Technology Antarctic Environmental Research (INCT-APA) that receives scientific and financial support from the National Council of Technological and Scientific Development (CNPq process: $n^{\circ}$ 574018/2008-5) and Carlos Chagas Research Support Foundation of the State of Rio de Janeiro (FAPERJ n E-16/170.023/2008). The authors also acknowledge the support of the Brazilian Ministries of Science, Technology and Innovation (MCTI), of Environment (MMA) and Inter-Ministry Commission for Sea Resources (CIRM). We thank Maria Días from BirdLife International for providing support with the seabird tracking database. This study benefited from the strategic program of MARE, financed by FCT (MARE UID/MAR/04292/2013).

\section{References}

ACAP. 2010. Species Assessment. Agreement on the Conservation of Albatrosses and Petrels, $<$ http://acap.aq/en/acap-species>.

Ackerly, D. D. et al. 2010. The geography of climate change: implications for conservation biogeography. - Divers. Distrib. 16: 476-487.

Adams, J. and Flora, S. 2009. Correlating seabird movements with ocean winds: linking satellite telemetry with ocean scatterometry. - Mar. Biol. 157: 915-929.

Ainley, D. G. and Hyrenbach, K. D. 2010. Top-down and bottom-up factors affecting seabird population trends in the California current system (1985-2006). - Prog. Oceanogr. 84: 242-254.

Allouche, O. et al. 2006. Assessing the accuracy of species distribution models: prevalence, kappa and the true skill statistic (TSS). - J. Appl. Ecol. 43: 1223-1232.

Anderson, O. R. J. et al. 2011. Global seabird bycatch in longline fisheries. - Endanger. Species Res. 14: 91-106.

Araújo, M. and New, M. 2007. Ensemble forecasting of species distributions. - Trends Ecol. Evol. 22: 4247. 
Araújo, M. B. et al. 2005. Validation of species-climate impact models under climate change. - Glob. Chang. Biol. 11: 1504-1513.

Barbet-Massin, M. et al. 2012. Selecting pseudo-absences for species distribution models: how, where and how many? - Methods Ecol. Evol. 3: 327-338.

Barbraud, C. et al. 2012. Effects of climate change and fisheries bycatch on Southern Ocean seabirds: a review. - Mar. Ecol. Prog. Ser. 454: 285-307.

Beaumont, L. J. and Hughes, L. 2002. Potential changes in the distributions of latitudinally restricted Australian butterfly species in response to climate change. - Glob. Chang. Biol. 8: 954-971.

Bellido, J. M. et al. 2011. Fishery discards and bycatch: solutions for an ecosystem approach to fisheries management? - Hydrobiologia 670: 317-333.

Bicknell, A. W. J. et al. 2013. Potential consequences of discard reform for seabird communities. - J. Appl. Ecol. 50: 649-658.

Birdlife International (2016a) Species factsheet: Thalassarche chrysostoma. Birdlife International, <http://www.birdlife.org/datazone/species/factsheet/22698398>.

Birdlife International (2016b) Species factsheet: Diomedea exulans. Birdlife International, <http://www.birdlife.org/datazone/species/factsheet/ 22698305>.

Brander, K. 2010. Impacts of climate change on fisheries. - J. Mar. Syst. 79: 389-402.

Bugoni, L. et al. 2008. Seabird bycatch in the Brazilian pelagic longline fishery and a review of capture rates in the southwestern Atlantic Ocean. - Endanger. Species Res. 5: 137-147.

Bull, L. S. 2007. Reducing seabird bycatch in longline, trawl and gillnet fisheries. - Fish Fish. 8: 31-56.

Burrows, M. T. et al. 2011. The pace of shifting climate in marine and terrestrial ecosystems. - Science 334: 652-5.

Catry, P. et al. 2013. Predicting the distribution of a threatened albatross: The importance of competition, fisheries and annual variability. - Prog. Oceanogr. 110: 1-10.

Cheung, W. W. L. et al. 2009. Projecting global marine biodiversity impacts under climate change 
scenarios. - Fish Fish. 10: 235-251.

Childs, C. 2004. Interpolating Surfaces in ArcGIS Spatial Analyst. - ArcUser July-September: 32-35.

Chown, S. L. et al. 2015. The changing form of Antarctic biodiversity. - Nature 522: 431-438.

Constable, A. J. et al. 2014. Climate change and Southern Ocean ecosystems I: How changes in physical habitats directly affect marine biota. - Glob. Chang. Biol. 20: 3004-3025.

Copello, S. and Quintana, F. 2009. Spatio-temporal overlap between the at-sea distribution of Southern Giant Petrels and fisheries at the Patagonian Shelf. - Polar Biol. 32: 1211-1220.

Cox, T. M. et al. 2007. Comparing effectiveness of experimental and implemented bycatch reduction measures: the ideal and the real. - Conserv. Biol. 21: 1155-64.

Croxall, J. P. 2002. Environmental Change and Antarctic Seabird Populations. - Science 297: 1510-1514.

Croxall, J. P. et al. 2005. Global Circumnavigations: Tracking Year-Round Ranges of Nonbreeding Albatrosses. - Science 307: 249-250.

Croxall, J. P. et al. 2012. Seabird conservation status, threats and priority actions: a global assessment. Bird Conserv. Int. 22: 1-34.

Daskalov, G. 2002. Overfishing drives a trophic cascade in the Black Sea. - Mar. Ecol. Prog. Ser. 225: 5363.

Daskalov, G. M. et al. 2007. Trophic cascades triggered by overfishing reveal possible mechanisms of ecosystem regime shifts. - Proc. Natl. Acad. Sci. U. S. A. 104: 10518-23.

Davies, R. W. D. et al. 2009. Defining and estimating global marine fisheries bycatch. - Mar. Policy 33 : $661-672$.

Dehnhard, N. et al. 2013. Good Days, Bad Days: Wind as a Driver of Foraging Success in a Flightless Seabird, the Southern Rockhopper Penguin. - PLoS One 8: e79487.

Delord, K. et al. 2008. Population trends in a community of large Procellariiforms of Indian Ocean: Potential effects of environment and fisheries interactions. - Biol. Conserv. 141: 1840-1856.

Doney, S. C. et al. 2012. Climate change impacts on marine ecosystems. - Ann. Rev. Mar. Sci. 4: 11-37. 
Dorresteijn, I. et al. 2012. Climate affects food availability to planktivorous least auklets Aethia pusilla through physical processes in the southeastern Bering Sea. - Mar. Ecol. Prog. Ser. 454: 207-220.

Dunne, J. P. et al. 2012. GFDL's ESM2 Global Coupled Climate-Carbon Earth System Models. Part I: Physical Formulation and Baseline Simulation Characteristics. - J. Clim. 25: 6646-6665.

Dunne, J. P. et al. 2013. GFDL's ESM2 Global Coupled Climate-Carbon Earth System Models. Part II: Carbon System Formulation and Baseline Simulation Characteristics*. - J. Clim. 26: 2247-2267.

Elith, J. et al. 2010. The art of modelling range-shifting species. - Methods Ecol. Evol. 1: 330-342.

Frederiksen, M. et al. 2006. From plankton to top predators: bottom-up control of a marine food web across four trophic levels. - J. Anim. Ecol. 75: 1259-68.

Frölicher, T. L. and Joos, F. 2010. Reversible and irreversible impacts of greenhouse gas emissions in multi-century projections with the NCAR global coupled carbon cycle-climate model. - Clim. Dyn. 35: 1439-1459.

Furness, R. W. et al. 2007. Influence of management practices and of scavenging seabirds on availability of fisheries discards to benthic scavengers. - Mar. Ecol. Prog. Ser. 350: 235-244.

García Molinos, J. et al. 2015. Climate velocity and the future global redistribution of marine biodiversity. - Nat. Clim. Chang. 6: 83-88.

Gilman, E. et al. 2005. Principles and approaches to abate seabird by-catch in longline fisheries. - Fish Fish. 6: 35-49.

Goberville, E. et al. 2015. Uncertainties in the projection of species distributions related to general circulation models. - Ecol. Evol. 5: 1100-1116.

González-Solís, J. et al. 2008. Offshore spatial segregation in giant petrels Macronectes spp.: differences between species, sexes and seasons. - Aquat. Conserv. Mar. Freshw. Ecosyst. 17: S22-S36.

González-Solís, J. et al. 2009. Influence of sea surface winds on shearwater migration detours. - Mar. Ecol. Prog. Ser. 391: 221-230.

Gorman, K. B. et al. 2010. A new high-latitude record for the macaroni penguin (Eudyptes chrysolophus) at Avian Island, Antarctica. - Polar Biol. 33: 1155-1158.

'This article is protected by copyright. All rights reserved.' 
Grémillet, D. and Boulinier, T. 2009. Spatial ecology and conservation of seabirds facing global climate change: a review. - Mar. Ecol. Prog. Ser. 391: 121-137.

Grémillet, D. et al. 2000. Black-browed albatrosses, international fisheries and the Patagonian Shelf. Mar. Ecol. Prog. Ser. 195: 269-280.

Hall, M. A. et al. 2000. By-Catch : Problems and Solutions. - Mar. Pollut. Bull. 41: 204-219.

Halpern, B. S. et al. 2008. A global map of human impact on marine ecosystems. Science 319: 948-952.

Halpern, B. S. et al. 2015. Spatial and temporal changes in cumulative human impacts on the world's ocean. - Nat. Commun. 6: 7615.

Harrington, J. M. et al. 2005. Wasted fishery resources: discarded by catch in the USA. - Fish Fish. 6: 350361.

Hazen, E. L. et al. 2012. Predicted habitat shifts of Pacific top predators in a changing climate. - Nat. Clim. Chang. 3: 234-238.

Hernández, P. A. et al. 2006. The effect of sample size and species characteristics on performance of different species distribution modeling methods. - Ecography 29: 773-785.

Hobday, A. J. et al. 2015a. Impacts of climate change on marine top predators: Advances and future challenges. - Deep Sea Res. Part II Top. Stud. Oceanogr. 113: 1-8.

Hobday, A. J. et al. 2015b. Reconciling conflicts in pelagic fisheries under climate change. - Deep Sea Res. Part II Top. Stud. Oceanogr. 113: 291-300.

Howarth, L. M. et al. 2014. The unintended consequences of simplifying the sea: making the case for complexity. - Fish Fish. 15: 690-711.

Hunt, G. L. and Schneider, D. C. 1987. Scale dependent processes in the physical and biological environment of marine birds. - In: Croxall J. P. (ed.), Seabirds feeding ecology and role in marine ecosystems. Cambridge University Press, pp. 7-41.

IPCC 2014. Climate Change 2014: Synthesis Report. Contribution of Working Groups I, II and III to the Fifth Assessment Report of the Intergovernmental Panel on Climate Change. - IPCC. 
Jiménez, S. et al. 2010. Assessing the impact of the pelagic longline fishery on albatrosses and petrels in the southwest Atlantic. - Aquat. Living Resour. 23: 49-64.

Jiménez-Valverde, A. and Lobo, J. M. 2007. Threshold criteria for conversion of probability of species presence to either-or presence-absence. - Acta Oecologica 31: 361-369.

Jones, M. C. et al. 2013. Predicting the impact of climate change on threatened species in UK waters. PLoS One 8: e54216.

Karpouzi, V. S. et al. 2007. Modelling and mapping resource overlap between seabirds and fisheries on a global scale: A preliminary assessment. - Mar. Ecol. Prog. Ser. 343: 87-99.

Kennicutt, M. C. et al. 2014a. A roadmap for Antarctic and Southern Ocean science for the next two decades and beyond. - Antarct. Sci. 27: 3-18.

Kennicutt, M. et al. 2014b. Six priorities for Antarctic science. - Nature 512: 23-25.

Klemas, V. 2013. Fisheries applications of remote sensing: An overview. - Fish. Res. 148: 124-136.

Kwon, T. S. and Lee, C. M. 2015. Prediction of abundance of ants according to climate change scenarios RCP 4.5 and 8.5 in South Korea. - J. Asia-Pacific Biodivers. 8: 49-65.

Kwon, T. S. et al. 2015. Prediction of abundance of beetles according to climate warming in South Korea. - J. Asia-Pacific Biodivers. 8: 7-30.

Lascelles, B. G. et al. 2016. Applying global criteria to tracking data to define important areas for marine conservation. - Divers. Distrib. DOI: 10.1111/ddi.12411

Legrand, B. et al. 2016. Current wintering habitat of an endemic seabird of Reunion Island, the Barau's petrel Pterodroma baraui, and predicted changes induced by global warming. - Mar. Ecol. Prog. Ser. 550: 235-248.

Lenoir, S. et al. 2011. Modelled spatial distribution of marine fish and projected modifications in the North Atlantic Ocean. - Glob. Chang. Biol. 17: 115-129.

Lewison, R. L. et al. 2014. Global patterns of marine mammal, seabird, and sea turtle bycatch reveal taxa-specific and cumulative megafauna hotspots. - Proc. Natl. Acad. Sci. U. S. A. 111: 5271-6. 
Liu, C. et al. 2009. Measuring the accuracy of species distribution models: a review. - World IMACS/MODSIM Congr. 18: 4241-4247.

Lozier, J. D. et al. 2009. Predicting the distribution of Sasquatch in western North America: Anything goes with ecological niche modelling. - J. Biogeogr. 36: 1623-1627.

Lu, B. et al. 2014. The GWmodel R package: further topics for exploring spatial heterogeneity using geographically weighted models. - Geo-spatial Inf. Sci. 17: 85-101.

Ludynia, K. et al. 2013. Sexual segregation in rockhopper penguins during incubation. - Anim. Behav. 85: $255-267$.

Mackley, E. et al. 2010. Free as a bird? Activity patterns of albatrosses during the nonbreeding period. Mar. Ecol. Prog. Ser. 406: 291-303.

Marzloff, M. P. et al. 2016. Modelling marine community responses to climate-driven species redistribution to guide monitoring and adaptive ecosystem-based management. - Glob. Chang. Biol. 22: 2462-2474.

Merow, C. et al. 2013. A practical guide to MaxEnt for modeling species' distributions: What it does, and why inputs and settings matter. - Ecography 36: 1058-1069.

Möllmann, C. et al. 2008. Effects of climate and overfishing on zooplankton dynamics and ecosystem structure: Regime shifts, trophic cascade, and feedback loops in a simple ecosystem. - ICES J. Mar. Sci. 65: 302-310.

Morin, X. and Thuiller, W. 2009. Comparing niche-and processe-based models to reduce prediction uncertainty in species range shifts under climate change. - Ecology 90: 1301-1313.

Nel, D. C. et al. 2003. Population dynamics of the wandering albatross Diomedea exulans at Marion Island: Longline fishing and environmental influences. - African J. Mar. Sci. 25: 503-517.

Ogier, E. M. et al. 2016. Fisheries management approaches as platforms for climate change adaptation: Comparing theory and practice in Australian fisheries. - Mar. Policy 71: 82-93.

Oksanen, J. et al. 2013. Community ecology package. CRAN, < http://vegan.r-forge.r-project.org/>.

Oppel, S. et al. 2012. Comparison of five modelling techniques to predict the spatial distribution and 'This article is protected by copyright. All rights reserved.' 
abundance of seabirds. - Biol. Conserv. 156: 94-104.

Paiva, V. et al. 2013a. Effects of environmental variability on different trophic levels of the North Atlantic food web. - Mar. Ecol. Prog. Ser. 477: 15-28.

Paiva, V. et al. 2013b. Overcoming difficult times: the behavioural resilience of a marine predator when facing environmental stochasticity. - Mar. Ecol. Prog. Ser. 486: 277-288.

Parmesan, C. N. 2006. Ecological and evolutionary responses to recent climate change. - Annu. Rev. Ecol. Evol. Syst. 37: 636-637.

Pascoe, S. et al. 2013. Economic and conservation implications of a variable effort penalty system in effort-controlled fisheries. - Appl. Econ. 45: 3880-3890.

Pauly, D. and Zeller, D. 2016. Catch reconstructions reveal that global marine fisheries catches are higher than reported and declining. - Nat. Commun. 7: 10244.

Pauly, D. et al. 1998. Diet composition and trophic levels of marine mammals. - ICES J. Mar. Sci. 55: 467481.

Pauly, D. et al. 2002. Towards sustainability in world fisheries. - Nature 418: 689-695.

Péron, C. et al. 2010. Interdecadal changes in at-sea distribution and abundance of subantarctic seabirds along a latitudinal gradient in the Southern Indian Ocean. - Glob. Chang. Biol. 16: 1895-1909.

Péron, C. et al. 2012. Projected poleward shift of king penguins' (Aptenodytes patagonicus) foraging range at the Crozet Islands, southern Indian Ocean. - Proc. R. Soc. B Biol. Sci. 279: 2515-2523.

Perry, A. L. et al. 2005. Climate Change and Distribution Shifts in Marine Fishes. - Science 308: 19121915.

Petry, M. V. et al. 2013. New southerly breeding location of king penguins (Aptenodytes patagonicus) on Elephant Island (Maritime Antarctic). - Polar Biol. 36: 603-606.

Phillips, R. A. et al. 2003. Effects of satellite transmitters on albatrosses and petrels. - Auk 120: 10821090.

Phillips, R. A. et al. 2004. Accuracy of geolocation estimates for flying seabirds. - Mar. Ecol. Prog. Ser. 
266: 265-272.

Phillips, R. A. et al. 2005. Summer distribution and migration of nonbreeding albatrosses: individual consistencies and implications for conservation. - Ecology 86: 2386-2396.

Phillips, R. A. et al. 2006. Year-round distribution of white-chinned petrels from South Georgia: Relationships with oceanography and fisheries. - Biol. Conserv. 129: 336-347.

Pinaud, D. and Weimerskirch, H. 2005. Scale-dependent habitat use in a long-ranging central place predator. - J. Anim. Ecol. 74: 852-863.

Pinaud, D. and Weimerskirch, H. 2007. At-sea distribution and scale-dependent foraging behaviour of petrels and albatrosses: a comparative study. - J. Anim. Ecol. 76: 9-19.

Pinnegar, J. K. et al. 2002. Long-term changes in the trophic level of the Celtic Sea fish community and fish market price distribution. - J. Appl. Ecol. 39: 377-390.

Planque, B. 2016. Projecting the future state of marine ecosystems, "la grande illusion"? - ICES J. Mar. Sci. 73: 204-208.

Quillfeldt, P. et al. 2013. Year-round distribution suggests spatial segregation of two small petrel species in the South Atlantic. - J. Biogeogr. 40: 430-441.

Quintana, F. et al. 2006. Population status and trends of Southern Giant Petrels (Macronectes giganteus) breeding in North Patagonia, Argentina. - Polar Biol. 30: 53-59.

R Core Team (2015) R: A language and environment for statistical computing. R Project, <https://www.rproject.org/>.

Ramírez, I. et al. 2013. Year-round distribution and habitat preferences of the Bugio petrel. - Mar. Ecol. Prog. Ser. 476: 269-284.

Reid, T. et al. 2013. Foraging range and habitat associations of nonbreeding Tristan albatrosses: overlap with fisheries and implications for conservation. - Endanger. Species Res. 22: 39-49.

Robinson, L. M. et al. 2015. Rapid assessment of an ocean warming hotspot reveals "high" confidence in potential species' range extensions. - Glob. Environ. Chang. 31: 28-37.

Rockström, J. et al. 2009. A safe operating space for humanity. - Nature 461: 472-475.

'This article is protected by copyright. All rights reserved.' 
Rolland, V. et al. 2010. Relative influence of fisheries and climate on the demography of four albatross species. - Glob. Chang. Biol. 16: 1910-1922.

Russell, D. et al. 2015. Predicting Future European Breeding Distributions of British Seabird Species under Climate Change and Unlimited/No Dispersal Scenarios. - Diversity 7: 342-359.

Santos, A. M. P. 2000. Fisheries oceanography using satellite and airborne remote sensing methods: a review. - Fish. Res. 49: 1-20.

Scales, K. L. et al. 2016. Identifying predictable foraging habitats for a wide-ranging marine predator using ensemble ecological niche models. - Divers. Distrib. 22: 212-224.

Scheffer, M. et al. 2005. Cascading effects of overfishing marine systems. - Trends Ecol. Evol. 20: 579581.

Sergio, F. et al. 2008. Top Predators as Conservation Tools: Ecological Rationale, Assumptions, and Efficacy. - Annu. Rev. Ecol. Evol. Syst. 39: 1-19.

Solanki, H. U. et al. 2005. Evaluation of remote-sensing-based potential fishing zones (PFZs) forecast methodology. - Cont. Shelf Res. 25: 2163-2173.

Stuart-Smith, R. D. et al. 2015. Thermal biases and vulnerability to warming in the world's marine fauna. - Nature 528: 88-92.

Sunday, J. M. et al. 2015. Species traits and climate velocity explain geographic range shifts in an oceanwarming hotspot. - Ecol. Lett. 18: 944-953.

Swartz, W. et al. 2010. The spatial expansion and ecological footprint of fisheries (1950 to present). PLoS One 5: 3-8.

Takao, S. et al. 2015. Projecting the impacts of rising seawater temperatures on the distribution of seaweeds around Japan under multiple climate change scenarios. - Ecol. Evol. 5: 213-223.

Tarroux, A. et al. 2016. Flexible flight response to challenging wind conditions in a commuting Antarctic seabird: Do you catch the drift? - Anim. Behav. 113: 99-112.

Thiebault, A. and Tremblay, Y. 2013. Splitting animal trajectories into fine-scale behaviorally consistent movement units: breaking points relate to external stimuli in a foraging seabird. - Behav. Ecol. 
Sociobiol. 67: 1013-1026.

Thomas, C. D. et al. 2004. Extinction risk from climate change. - Nature 427: 145-148.

Thomson, R. B. et al. 2015. Effects of climate change and fisheries bycatch on shy albatross

(Thalassarche cauta) in Southern Australia. - PLoS One 10: 1-25.

Thuiller, W. 2003. BIOMOD: Optimising predictions of species distributions and projecting potential future shift under global change. - Glob. Chang. Biol. 9: 1353-1362.

Thuiller, W. 2004. Patterns and uncertainties of species' range shifts under climate change. - Glob. Chang. Biol. 10: 2020-2027.

Thuiller, W. et al. 2009. BIOMOD - A platform for ensemble forecasting of species distributions. Ecography 32: 369-373.

Thuiller, A. W. et al. 2014. Ensemble platform for species distribution modeling. CRAN, <https://cran.rproject.org/web/packages/biomod2/index.html>.

Tuck, G. N. et al. 2011. An assessment of seabird-fishery interactions in the Atlantic Ocean. - ICES J. Mar. Sci. 68: 1628-1637.

VanDerWal, J. et al. 2009. Selecting pseudo-absence data for presence-only distribution modeling: How far should you stray from what you know? - Ecol. Modell. 220: 589-594.

Vitousek, P. M. et al. 1997. Human Domination of Earth's Ecosystems. - Science 277: 494-499.

Votier, S. C. et al. 2004. Changes in fisheries discard rates and seabird communities. - Nature 427: 727730.

Walther, G.-R. 2010. Community and ecosystem responses to recent climate change. - Philos. Trans. R. Soc. Lond. B. Biol. Sci. 365: 2019-24.

Watson, R. et al. 2006. Fishing gear associated with global marine catches. I. Database development. Fish. Res. 79: 97-102.

Waugh, S. M. et al. 1999. Population dynamics of Black-browed and Grey-headed Albatrosses Diomedea melanophrys and D. chrysostoma at Campbell Island, New Zealand, 1942-96. - Ibis 141: 216-225. 
Waugh, S. M. et al. 2008. CCAMLR process of risk assessment to minimise the effects of longline fishing mortality on seabirds. - Mar. Policy 32: 442-454.

Weimerskirch, H. et al. 2012. Changes in Wind Pattern Alter Albatross Distribution and Life-History Traits. - Science 335: 211-214.

Williams, H. W. et al. 2015. Climate suitability for European ticks: assessing species distribution models against null models and projection under AR5 climate. - Parasit. Vectors 8: 440.

Wisz, M. S. et al. 2008. Effects of sample size on the performance of species distribution models. Divers. Distrib. 14: 763-773.

Worm, B. et al. 2006. Impacts of Biodiversity Loss on Ocean Ecosystem Services. - Science 314: 787-790.

Worm, B. et al. 2009. Rebuilding Global Fisheries. - Science 325: 578-585.

Xavier, J. C. et al. 2004. Foraging ecology and interactions with fisheries of wandering albatrosses (Diomedea exulans) breeding at South Georgia. - Fish. Oceanogr. 13: 324-344.

Xavier, J. C. et al. 2006. Determining prey distribution patterns from stomach-contents of satellitetracked high-predators of the Southern Ocean. - Ecography 29: 260-272.

Yeh, Y.-M. et al. 2013. Estimates of seabird incidental catch by pelagic longline fisheries in the South Atlantic Ocean. - Anim. Conserv. 16: 141-152.

Zhang, L. et al. 2015. Consensus forecasting of species distributions: The effects of niche model performance and niche properties. - PLoS One 10: 1-18.

Zhou, S. et al. 2010. Ecosystem-based fisheries management requires a change to the selective fishing philosophy. - Proc. Natl. Acad. Sci. 107: 9485-9489.

Žydelis, R. et al. 2013. The incidental catch of seabirds in gillnet fisheries: A global review. - Biol. Conserv. 162: 76-88.

Supplementary material (Appendix ECOG-02590 at <www.oikosoffice.lu.se/appendix/ecog-02590>). Appendix 1. 


\section{Figure Legends}

Figure 1. Species probability of occurrence from zero (blue) to one (red) and the predicted area of occurrence above the models' thresholds (dashed black line), contrasted to the median area of occurrence for all the climate change scenarios together (solid black line). Black-browed Albatross (BBA), Greyheaded Albatross (GHA), Northern Giant Petrel (NGP), Southern Giant Petrel (SGP), Tristan Albatross (TA), Wandering Albatross (WA) and White-chinned Petrel (WCP).

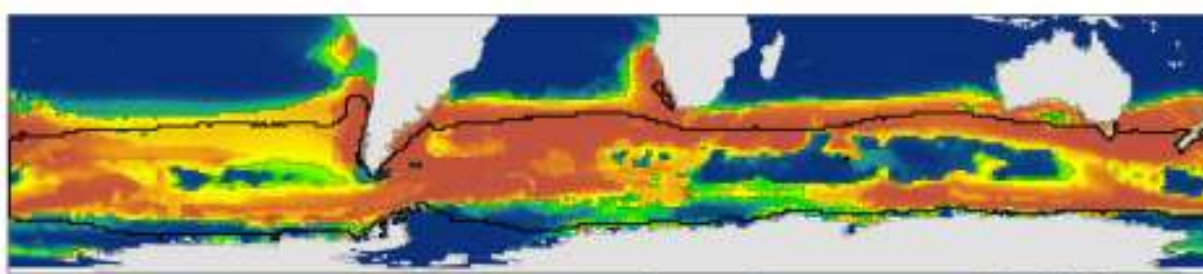

BBA

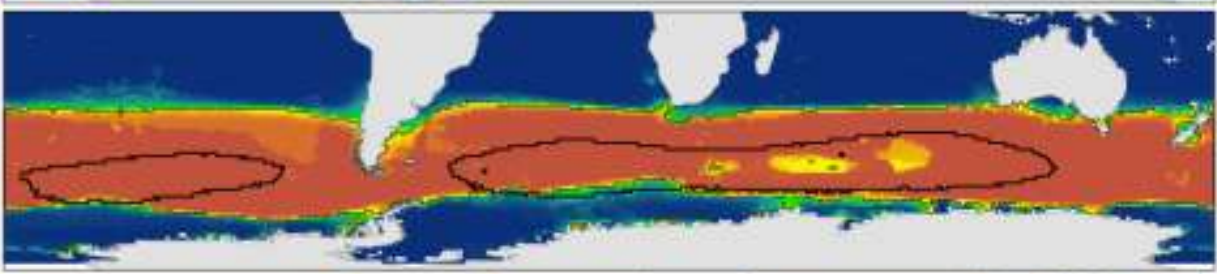

\section{GHA}

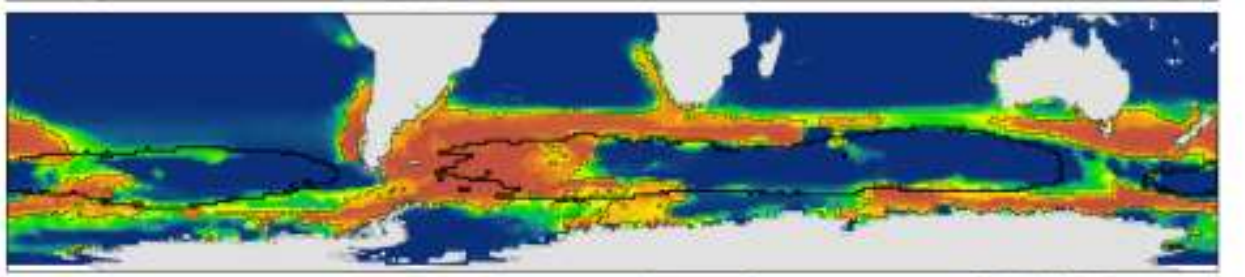

NGP
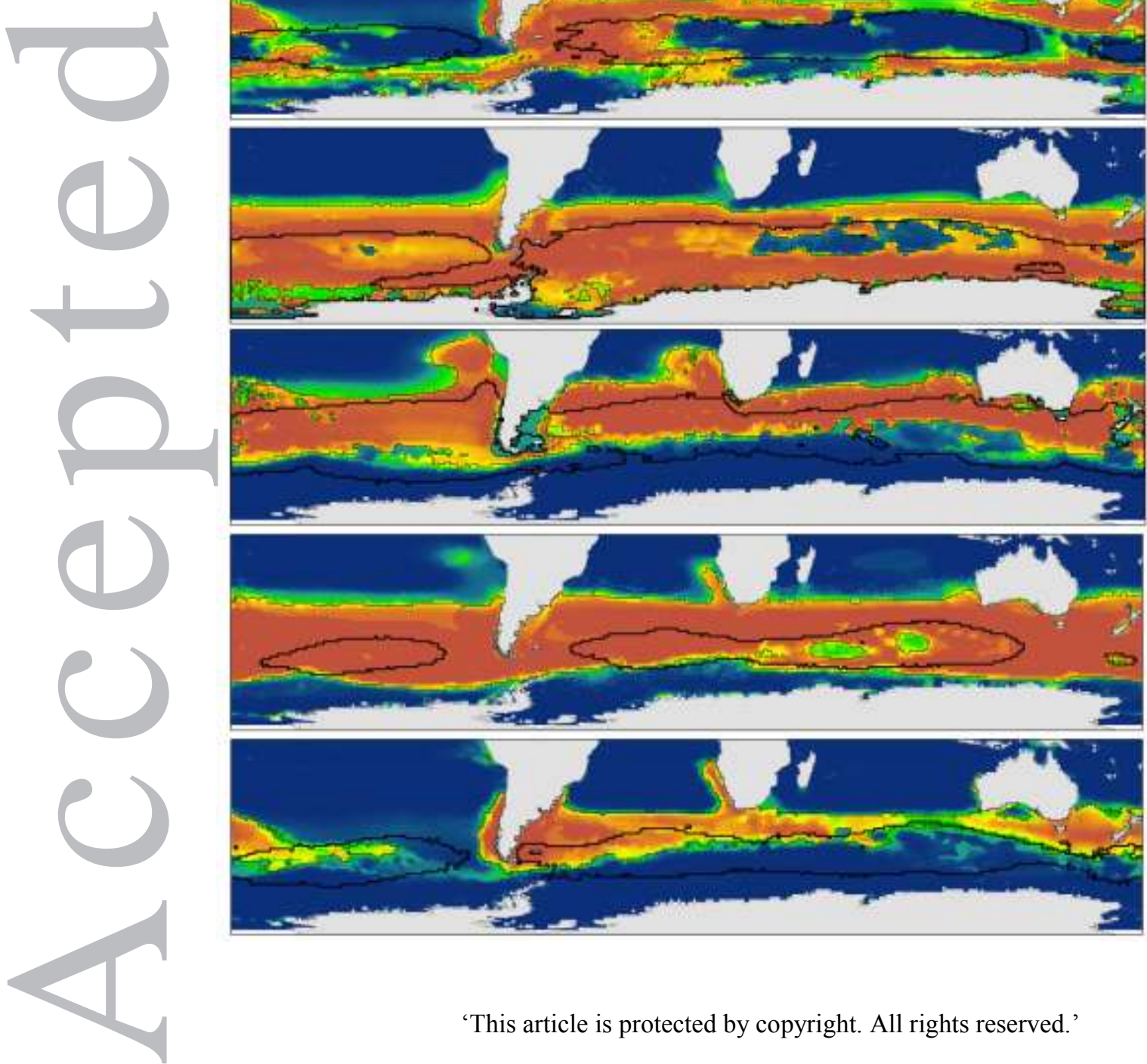

\section{SGP}

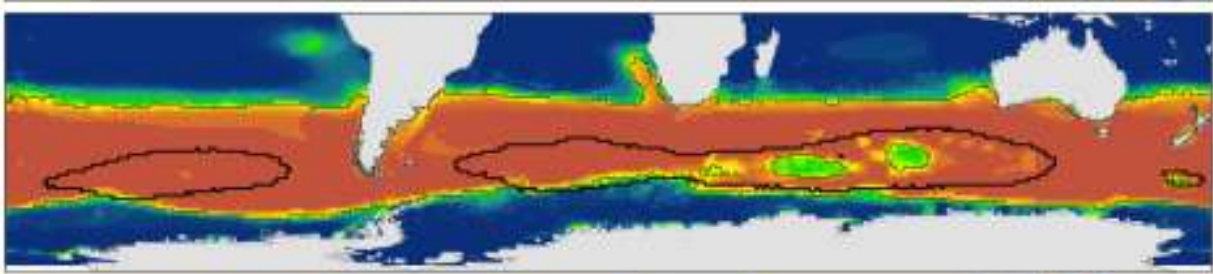

WA

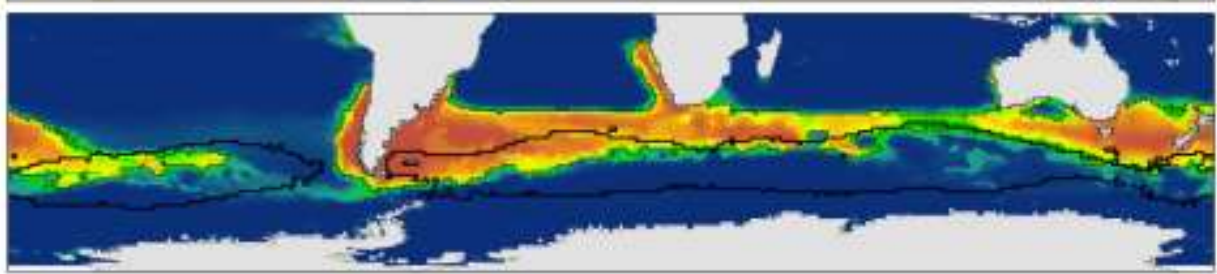

WCP

'This article is protected by copyright. All rights reserved.' 
Figure 2. High and Low Bycatch Fisheries probability of occurrence from zero (blue) to one (red) and the predicted area of occurrence above the models' thresholds (dashed black line), contrasted to the median area of occurrence for all the climate change scenarios together (solid black line).
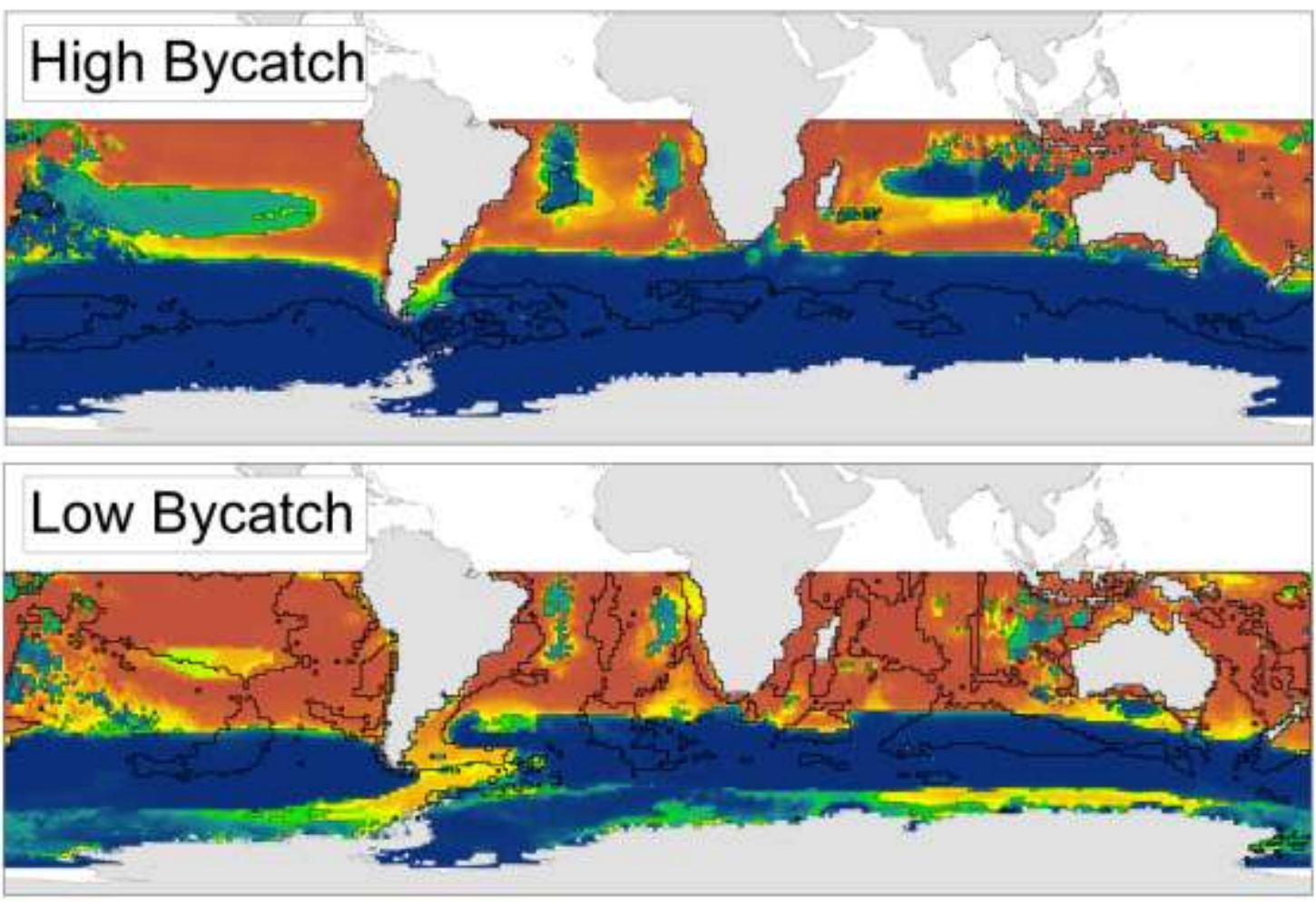
Figure 3. Mean \pm SD (a) latitude shift and (b) species range change of Black-browed Albatross (BBA), Grey-headed Albatross (GHA), Northern Giant Petrel (NGP), Southern Giant Petrel (SGP), Tristan Albatross (TA), Wandering Albatross (WA) and White-chinned Petrel (WCP).
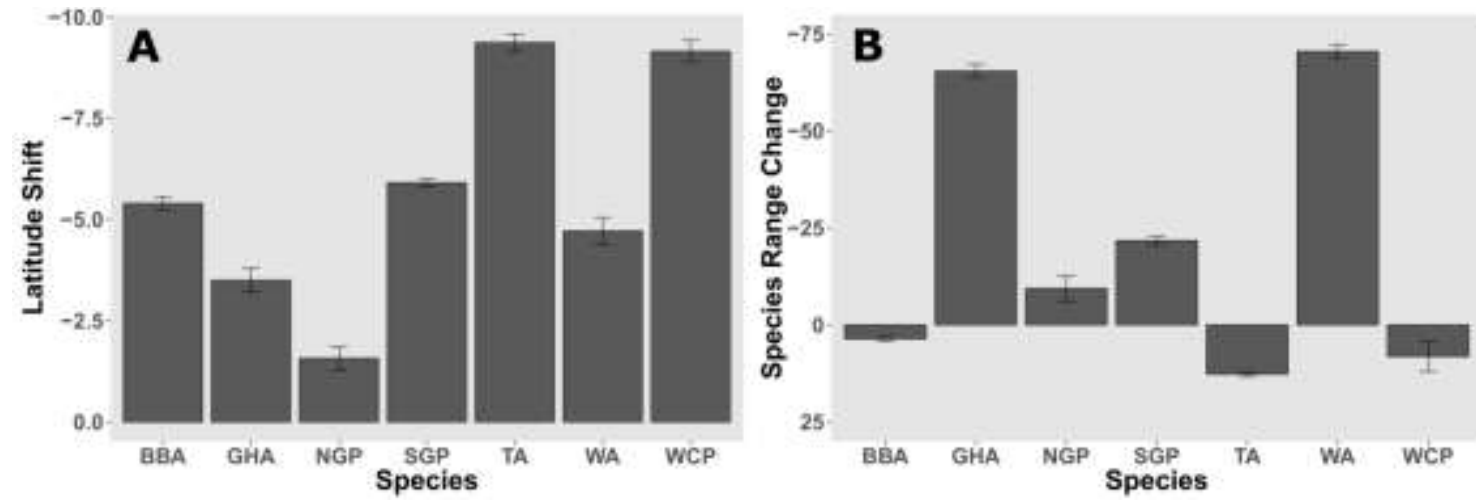
Figure 4. Biplot of the Geographically Weighted Principal Component Analysis showing the species and fisheries centroid Prediction (a) and Projections for year 2100 over climate change scenarios RCP 2.6 (b), RCP 4.5 (c), RCP 6.0 (d) and RCP 8.5 (e) representing the shifts in species and fisheries overlaps, and the mean GWPCA bi-dimensional distance of species from high-bycatch fisheries (f) and lowbycatch fisheries $(\mathrm{g})$ on projections in relation to the prediction. Black-browed Albatross (BBA), Greyheaded Albatross (GHA), Northern Giant Petrel (NGP), Southern Giant Petrel (SGP), Tristan Albatross (TA), Wandering Albatross (WA), White-chinned Petrel (WCP), High-bycatch Fisheries (HIGH) and Low-bycatch Fisheries (LOW).
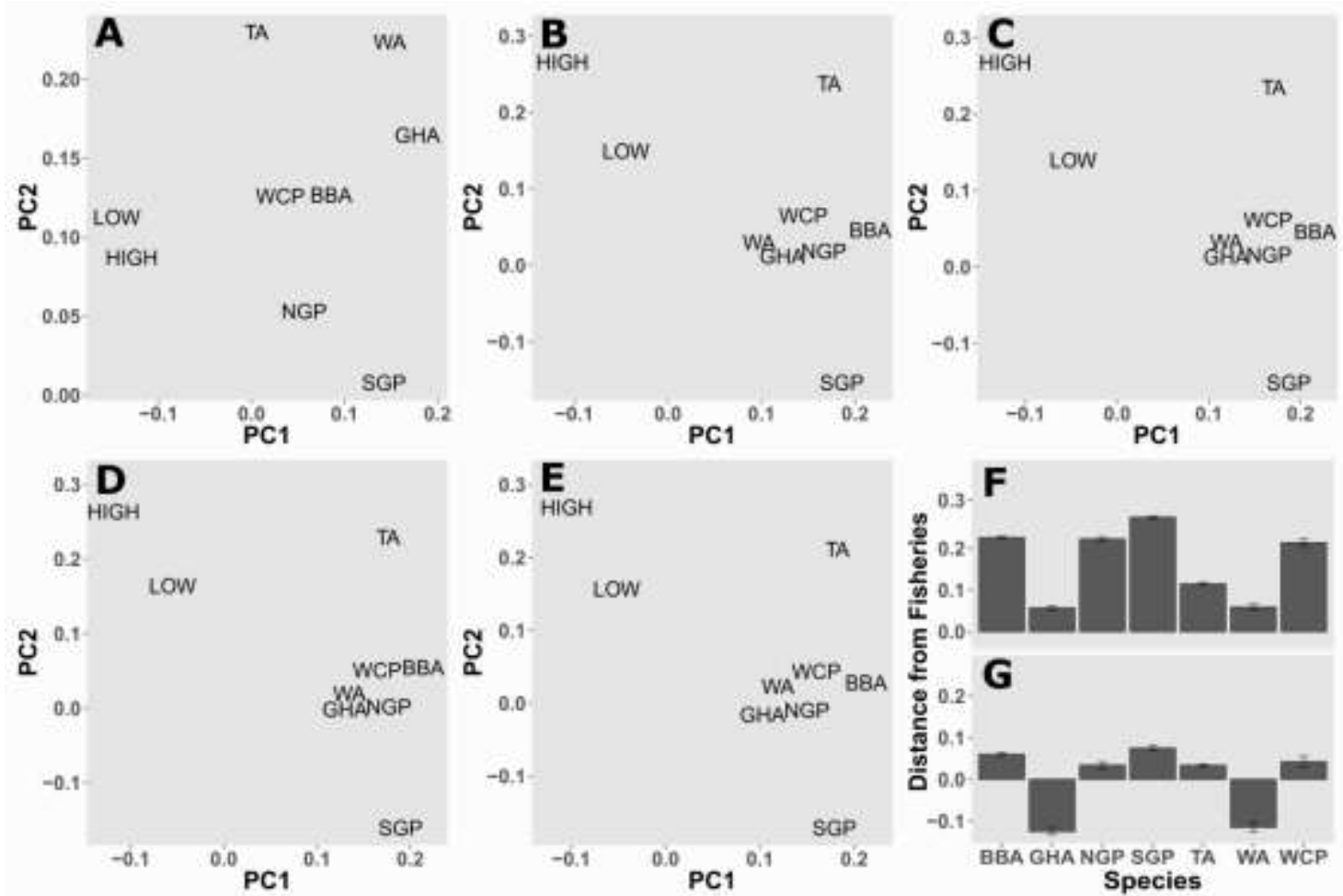

'This article is protected by copyright. All rights reserved.' 
Figure 5.Cross-Validation (CV) scores coefficients of the Geographically Weighted Principal Component Analysis, representing the spatiality of shifts in species and fisheries overlaps, and lines of the distribution limits of fisheries types and species in the scenarios. The warm colours indicate zones of higher CV scores, where there was the greater amount of shifts and overlap of species and fisheries in the projected scenarios.

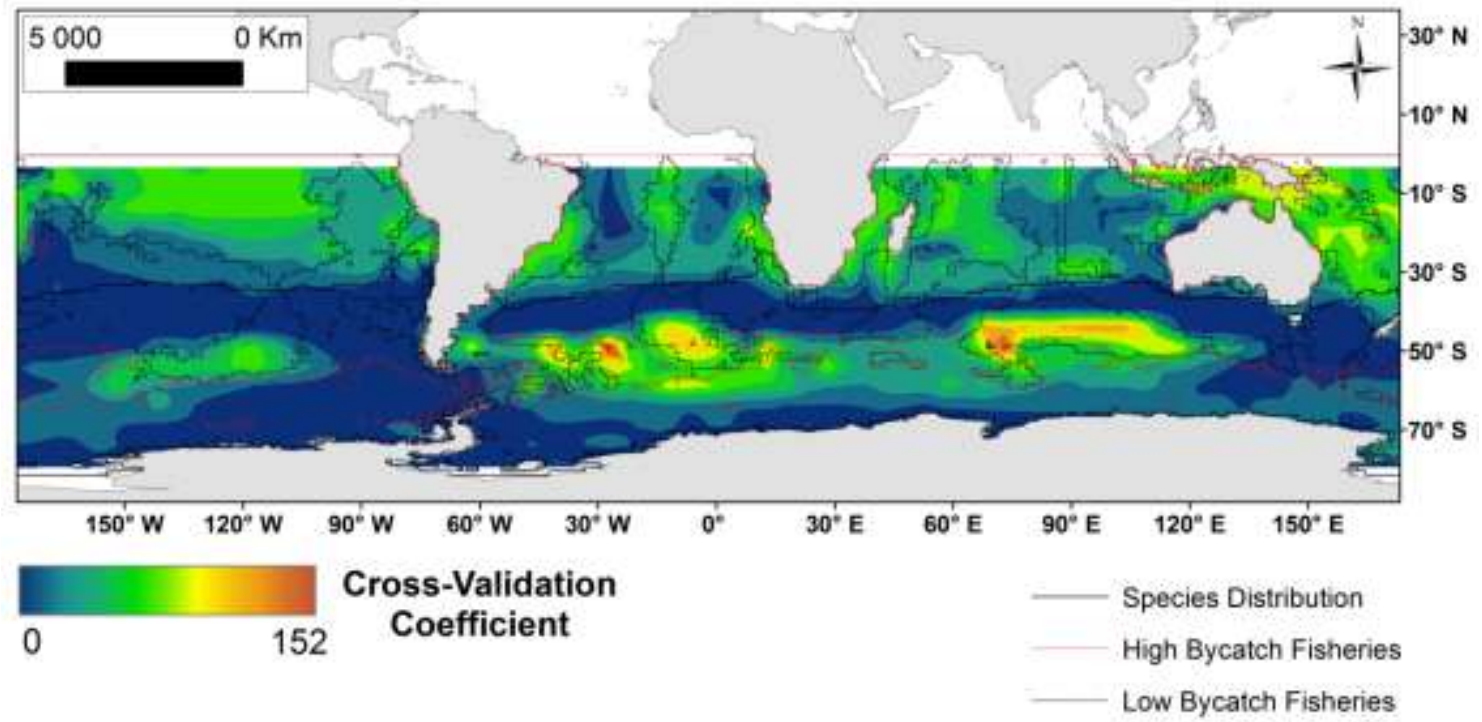

'This article is protected by copyright. All rights reserved.' 